\title{
The Prevalence and Determinants of Using Withdrawal to Avoid Pregnancy in Tabriz, Iran
}

\author{
Hajiieh Bibi Razeghi Nasrabad $^{1}$, Malihe Alimondegari ${ }^{2 *}{ }^{(}$, Zeinab Mohseni Nejhad $^{2}$
}

\begin{abstract}
Objectives: Despite the increasing knowledge about family planning and modern contraceptive methods, as well as high failure rates of the traditional method, a significant percentage of couples use withdrawal for contraception. Accordingly, the present study mainly aimed to investigate the determinants of using withdrawal to avoid pregnancy in Tabriz.

Materials and Methods: The sample of the study included 383 married women aged 15-49 years. Multivariate logistic regression analyses were employed to determine factors associated with using withdrawal as a contraceptive method.

Results: Based on the results, about $19.5 \%$ of the women were relying on withdrawal. In addition, $55 \%$ reported that they were currently using a modern method to avoid pregnancy while the remaining $25.5 \%$ used no method in order to prevent contraception. The results of multivariate logistic regression demonstrated that university-educated couples with no child who were within the age range of 15-24 and born in urban areas were more likely to use withdrawal rather than modern contraceptive methods $(\mathrm{P}<0.05)$.

Conclusions: In general, the rate of employing the traditional method in Iran and, especially in Tabriz is increasing. Regarding higher proportion of withdrawal use among higher educated women due to the fear of side effects resulted from other methods, family planning providers and reproductive health services should be sensitive to the women's concern and provide programs to decrease the unmet need of family planning.

Keywords: Traditional method, Fertility, Withdrawal, Contraceptive method
\end{abstract}

\section{Introduction}

Withdrawal is an old main traditional method which is used by the couples in many societies for regulating the births in the early stages of the fertility transition (1-4). During the 1980s, over two-fifths (42.3\%) of urban couples employed withdrawal. In fact, when other methods were not readily available, withdrawal played an important role in reducing fertility in urban areas of Iran (5).

After restarting the population policy in the 1980s, contraceptive methods became available throughout the country and their use rose from $49 \%$ to $70 \%$ in 1990 (6). In addition, the proportion of married women using modern contraceptive methods increased from $26 \%$ in 1976 (7) to $56.98 \%$ in 2011 (8).

However, at present, significant proportions of Iranian couples rely on withdrawal in order to avoid unwanted pregnancy. According to 2011 demographic and health survey (DHS), the prevalence rate of withdrawal was $21.10 \%$ (i.e., $24.36 \%$ in urban and $13.40 \%$ in rural areas) among the currently married women whose age varied from 15 to 49 years old (8). It is noted that the failure rate of withdrawal is between 4 and $24 \%$ (9) while the rate of pill and IUD failure is 3 and 1\%, respectively (10). The probability of unwanted pregnancy and subsequent induced abortion may increase due to the high rate of failure of withdrawal. In 2000 , nearly $7.8 \%$ of unwanted pregnancy was estimated to be related to withdrawal $(11,12)$.

The current study mainly sought to examine the determinants of employing withdrawal among the couples who lived in Tabriz. Based on 2000 and 2010 DHS, using this contraceptive method increased from $14.3 \%$ to $17.37 \%$ in East Azarbayjan province $(7,8)$. However, women's mortality rates may increase due to high failure rates of this method, as well as the risk of unwanted pregnancy and abortion (12). Thus, from the perspective of public health and population policy, identifying the factors which affect the use of withdrawal instead of other methods is of great significance.

Studying the prevalence of withdrawal and its determinants is important in new demographic conditions in Iran. Based on the literature review, the majority of women rely on traditional methods due to the lack of family planning services or inadequate knowledge regarding family planning (13). The providers of family planning and reproductive health services are considered important sources of comprehensive information about family planning and therefore, their idea and knowledge respecting the efficacy or adverse effects of contraception methods can influence the women's choices in this regard 
(14). Accordingly, identifying those women who use these methods is essential for health care providers. The findings of this study can be helpful for health care providers for improving health services.

In this study, it was hypothesized that factors associated with withdrawal operate in various aspects. As a result, the social, socio-economic and demographic factors, gender preference, and intention regarding having more children were regarded as the main factors of withdrawal in this framework.

\section{Materials and Methods}

The data source was a survey entitled "The gap between actual and ideal fertility in Tabriz" (15). Those women who were pregnant were excluded from the study. The samples contained a total of 383 currently married women aged 15-49. Further, they were selected by multi-stage stratified random sampling technique from different regions of Tabriz. Furthermore, a structured questionnaire was used to collect related data.

Moreover, the purpose of the research was described for all the respondents before administering the interview and it was started upon their agreement.

Questionnaire reported contraceptive use by the following question, 'Are you or your husband currently using any method to delay or avoid a pregnancy?' Those who responded 'Yes' were further requested to mention the method they were using. The options included not using Pill, condom, female or male sterilization, injection, IUD, withdrawal, or implants/norplant. Considering these categories, the dependent variables were divided into modern contraceptive methods and withdrawal categories. Based on the conceptual framework, place of birth, gender preference, the number of living children, age, education, home ownership, employment status, and duration of marriage were considered independent variables which were included in the analyses. Additionally, percentage and chi-squared testing were used in the bivariate analysis. In addition, binary logistic regression was employed to study the effect of covariates on the risk of withdrawal. Finally, the SPSS software, version 24 was applied to analyze the data. The $P$ values of less than 0.05 were considered statistically significant. Further, the results of the study were analyzed in terms of the odds ratio with a $95 \%$ confidence interval. Various instruments including Hosmer and Lemeshow (H-L), as well as Cox-Snell R-squared and Nagelkerke R-squared tests were utilized to evaluate the regression models.

\section{Results}

The distribution of currently married women aged 15-49 years by the contraceptive method indicated that $25.5 \%$ of these women within the age of 15-49 used no method for contraception. Among the contraceptive users, 26.1\% relied on withdrawal while73.9 \% of them reported that they were currently using a modern contraceptive method.
Table 1 demonstrates the distribution of currently married women (aged 15-49 years) by using a modern contraceptive method, along with withdrawal and sociodemographic variables. The highest rate of withdrawal $(50 \%)$ is related to women aged 15-19 while those within the age range of 40-49 have the lowest rate of withdrawal use $(17.2 \%)$. As regards the duration of the marriage, the results represent similar patterns of withdrawal use. In other words, totally, $37 \%$ of the women married for less than 5 years reported using withdrawal and $19.5 \%$ of women who were married for 10 years and above were relying on withdrawal $(P<0.002)$.

Further, the proportion of withdrawal users rises with women's level of education. All the illiterate women use modern contraception. Only $7.1 \%$ of the women with primary education rely on withdrawal while over $28 \%$ of diploma women and $33.6 \%$ of women with university education indicate using withdrawal $(P<0.008)$.

The number of living children and intention fertility are regarded as important factors which can affect withdrawal usage. Accordingly, 33.1\% of the women who have an intention for more children indicate using withdrawal while $20.9 \%$ of those who have no intention to have more children rely on withdrawal $(P<0.007)$. Furthermore, $43.3 \%$ of childless women have reported using withdrawal. Conversely, $12.9 \%$ of women with three and more children preferred using withdrawal $(P<0.007)$.

Additionally, the current contraceptive used method was compared concerning gender preference for the sex of the next child, home ownership, and employment status. The results of the chi-square test represented no significant relationship between these three variables and type of contraception method $(P>0.05)$.

In general, the lowest rate of withdrawal use was observed in women aged 40-49 who were illiterate, married for less than 5 years, and had 3 and more parity while they had no intention for more children. Contrarily, higher educated women who were born in an urban area, younger women, and those with no child had the highest rate of using withdrawal.

The results of logistic regression are represented in Table 2. Using withdrawal is significantly more likely among 15 $19(\mathrm{~B}=0.197$, Wald $=5.25, P<0.05)$ and 20-24 $(\mathrm{B}=0.296$, Wald $=3.73, P<0.05)$ women compared to those aged 40 49. In addition, the likelihood of using withdrawal among childless women is $64 \%$ more than those who have three children and more. Further, women with a primary and secondary level of education are 0.176 and 0.239 times less likely to rely on this method compared to women with university education.

Furthermore, women who have the intention to have more children are $46 \%$ more likely to use withdrawal rather than modern methods. Moreover, women who born in urban areas are 1.84 times more likely to use withdrawal than women from rural areas. Explained variance by CoxSnell R-squared and Nagelkerke R-squared measures are 
Razeghi Nasrabad et al

Table 1. Percentage Distribution of Currently Married Women Using the Contraceptive Method

\begin{tabular}{|c|c|c|c|c|c|c|}
\hline Variable & & Modern (\%) & Withdrawal (\%) & $\mathrm{N}$ & Chi-square Value & $P$ Value \\
\hline \multirow{6}{*}{ Age group } & $15-19$ & 50 & 50 & 18 & \multirow{6}{*}{12.05} & \multirow{6}{*}{0.034} \\
\hline & $20-24$ & 78.6 & 21.4 & 28 & & \\
\hline & $25-29$ & 76.1 & 23.9 & 67 & & \\
\hline & $30-34$ & 67.7 & 32.3 & 130 & & \\
\hline & $35-39$ & 78.9 & 21.1 & 76 & & \\
\hline & $40-49$ & 82.8 & 17.2 & 64 & & \\
\hline \multirow{3}{*}{ Duration of marriage } & $<5$ & 63.1 & 36.9 & 65 & \multirow{3}{*}{12.15} & \multirow{3}{*}{0.002} \\
\hline & $5-9$ & 66 & 34 & 97 & & \\
\hline & $10+$ & 80.5 & 19.5 & 221 & & \\
\hline \multirow{4}{*}{ Number of living children } & 0 & 56.7 & 43.3 & 30 & \multirow{4}{*}{11.63} & \multirow{4}{*}{0.009} \\
\hline & 1 & 70.9 & 29.1 & 141 & & \\
\hline & 2 & 73.9 & 26.1 & 142 & & \\
\hline & $3+$ & 87.1 & 12.9 & 70 & & \\
\hline \multirow{2}{*}{ Employment status } & Employed & 70.8 & 29.2 & 96 & \multirow[t]{2}{*}{0.621} & \multirow[t]{2}{*}{0.431} \\
\hline & Unemployed & 74.9 & 25.1 & 286 & & \\
\hline \multirow{6}{*}{ Level of education } & Illiterate & 100 & 0 & 11 & \multirow{6}{*}{15.61} & \multirow{6}{*}{0.008} \\
\hline & Primary & 92.9 & 7.1 & 28 & & \\
\hline & Secondary & 81 & 19 & 42 & & \\
\hline & High school & 80.6 & 19.4 & 36 & & \\
\hline & Diploma & 71.9 & 28.1 & 114 & & \\
\hline & University & 66.4 & 33.6 & 152 & & \\
\hline \multirow{3}{*}{ Gender preference } & Girl & 73.3 & 26.7 & 75 & \multirow{3}{*}{2.13} & \multirow{3}{*}{0.343} \\
\hline & Boy & 79.6 & 20.4 & 93 & & \\
\hline & No different & 71.6 & 28.4 & 215 & & \\
\hline \multirow{2}{*}{ Intention to more children No } & Yes & 66.9 & 33.1 & 163 & \multirow{2}{*}{7.24} & \multirow{2}{*}{0.007} \\
\hline & No & 79.1 & 20.9 & 220 & & \\
\hline \multirow{3}{*}{ Home ownership } & Personal home & 77.8 & 22.2 & 89 & \multirow{3}{*}{5.29} & \multirow{3}{*}{0.071} \\
\hline & Rental & 66.3 & 33.7 & 243 & & \\
\hline & Free & 68.6 & 31.4 & 51 & & \\
\hline \multirow{2}{*}{ Place of birth } & Urban & 70.6 & 29.4 & 282 & \multirow{2}{*}{6.12} & \multirow{2}{*}{0.008} \\
\hline & Rural & 83.2 & 16.8 & 101 & & \\
\hline Total & - & 73.9 & 26.1 & 383 & - & - \\
\hline
\end{tabular}

Table 2. Regression Model for Predicting Withdrawal Usage by the Couples in Tabriz

\begin{tabular}{|c|c|c|c|c|c|c|}
\hline Variable & & B & SE & Wald & $P$ Value & $\operatorname{Exp}(B)$ \\
\hline \multirow{5}{*}{ Age group (ref. 45-49) } & $15-19$ & -1.625 & 0.709 & 5.255 & 0.022 & 0.197 \\
\hline & $20-24$ & -1.217 & 0.630 & 3.736 & 0.043 & 0.296 \\
\hline & $25-29$ & -.276 & 0.705 & 0.153 & 0.695 & 0.759 \\
\hline & $30-34$ & -.669 & 0.769 & 0.757 & 0.384 & 0.512 \\
\hline & $35-39$ & -.387 & 0.875 & 0.196 & 0.658 & 0.679 \\
\hline \multirow{3}{*}{ Number of living children (ref. $3+$ ) } & 0 & 0.044 & 0.799 & 0.013 & 0.002 & 1.64 \\
\hline & 1 & 0.268 & 0.453 & 0.351 & 0.554 & 1.307 \\
\hline & 2 & -0.244 & 0.544 & 0.201 & 0.654 & 0.783 \\
\hline Place of birth (ref. rural) & Urban & 0.614 & 0.324 & 3.580 & 0.048 & 1.847 \\
\hline \multirow{4}{*}{ Level of education (ref. university) } & Illiterate \& primary & -1.736 & 0.785 & 4.893 & 0.027 & 0.176 \\
\hline & Secondary & -1.514 & 0.696 & 2.074 & 0.041 & 0.239 \\
\hline & High school & -.0705 & 0.511 & 1.905 & 0.168 & 0.494 \\
\hline & Diploma & -0.213 & 0.294 & 0.525 & 0.469 & 0.808 \\
\hline Intention to more children (ref. No) & Yes & 0.038 & 0.330 & 1.840 & 0.021 & 1.464 \\
\hline
\end{tabular}

2 Log likelihood = 397.322; Cox \& Snell R Square = 0.105; Nagelkerke R Square $=0.154$. 
10.5 and $15.4 \%$, respectively.

\section{Discussion}

Despite a considerable decline in fertility, increasing knowledge concerning family planning and modern contraceptive methods, along with the high failure rate of the traditional method, a significant percentage of couples use withdrawal for contraception. The current study examined the contraceptive behavior of women in Tabriz in order to better understand the factors associated with the prevalence of withdrawal use.

Based on the findings, withdrawal, pills, IUD, and condom were the most popular conceptive methods in Tabriz. Additionally, the results revealed that $25.5 \%$ of the currently married women aged 15-49 employed no method for contraception. Nearly $26.1 \%$ of the contraceptive users applied withdrawal to prevent unwanted pregnancy.

In addition, the highest rate of withdrawal usage was related to women aged 15-24. Therefore, family planning services should pay more attention to this age group. This result is consistent with the findings of Aghajanian et al (5), Azari et al (16), and Ergocmen et al (17). These studies reported that withdrawal was more common among young individuals (18).

Further, the number of living children and negative fertility intention were considered significant predictors which negatively influenced the withdrawal. The percentage of women using withdrawal was extremely lower among women with 3 and more parity. However, childless women had the highest rate of using withdrawal. Furthermore, the tendency of women to use withdrawal would be higher if they had an intention to have more children. These findings are in line with those of other studies indicating the role of the number of living children in their contraceptive method choice $(19,20)$. Based on the results of the current study, younger women with lower parity are more likely to prefer withdrawal. This can be due to an increase in the level of education among the young generation. Conversely, based on the results of multivariate analysis, the likelihood of using withdrawal was lower among women with primary education compared to more educated women. Other studies $(21,22)$ found that there was less likelihood of using withdrawal among illiterate and primary women compared to those with college degrees.

However, in some societies, women with university education had the lowest levels of withdrawal use $(23,24)$. According to Whittaker et al (23), several males and females aged 18-25 who used withdrawal received some information at school or from a health center about this method. Jones et al (24) investigated contraceptive practices and withdrawal in women aged 18-39 in the Unites States. Based on their results, only $8 \%$ of women with college degrees reported employing this method.

Why a considerable proportion of better educated and younger women use withdrawal instead of modern contraceptive? Regarding the proportion of withdrawal use by education and home ownership and place of birth, it seems that use of this method is not due to low level of knowledge about contraception or lack of access to modern methods. Conversely, women with university education level and those who were born in urban areas were more likely to use withdrawal rather than the modern method.

Moreover, the high rate of withdrawal use is expected to be associated with a higher rate of fertility. However, according to 2011 DHS data, the highest prevalence of withdrawal belonged to Ghom, Guilan, Mazandaran, Tehran, and Semnan provinces, all of which had a low level of replacement fertility (8).

It is noteworthy that the rate of failure of this method was high, and the high rate of unwanted pregnancy resulting from this method was reported in many studies. Several studies demonstrated that the highest prevalence of unwanted pregnancies was related to women who used traditional methods $(12,25,26)$. Razeghi Nasrabad et al (26) found that $64 \%$ of women who reported unplanned pregnancy were using the traditional prepregnancy contraceptive method. Based on the results a number of qualitative studies, fear of side effects, lack of or less trust in modern methods, the comfort of use and husband's opposition regarding using other methods were considered as the main reasons which women tended to use withdrawal instead of modern methods $(23,27)$.

\section{Conclusions}

In general, the results indicated that a significant percentage of couples employ withdrawal for contraception despite a considerable decline in fertility, an increase in knowledge about family planning and modern contraceptive methods, and high failure rates of the traditional method.

Therefore, couples need to access sufficient and accurate knowledge regarding modern contraceptive methods. Accordingly, the providers of family planning and reproductive health services should be sensitive to the women's concerns about the side effects of contraceptive methods and thus provide programs to decrease the unmet needs of family planning.

\section{Conflict of Interests}

Authors declare that they have no conflict of interests.

\section{Ethical Issues}

There was no need to create a committee of ethics and obtain the ethical code since no tests were conducted on women. Of course, the current study was accepted at the Academic Council College under the approval number of 2378113.

\section{Financial Support}

This study was supported by Faculty of Social Science, Yazd University. 


\section{Acknowledgments}

The present study was based on a thesis entitled "The gap between actual and ideal fertility in Tabriz" which was submitted in Demography Department, Faculty of Social Science, Yazd University (No. 2378113).

\section{References}

1. Rossier C, Corker J. Contemporary Use of Traditional Contraception in sub-Saharan Africa. Popul Dev Rev. 2017;43(Suppl 1):192-215. doi:10.1111/padr.12008

2. Bongaarts J, Westoff CF. The potential role of contraception in reducing abortion. Stud Fam Plann. 2000;31(3):193-202.

3. Marston C, Cleland J. Relationships between contraception and abortion: a review of the evidence. Int Fam Plan Perspect. 2003;29(1):6-13. doi:10.1363/ifpp.29.006.03

4. Myntti C, Ballan A, Dewachi O, El-Kak F, Deeb ME. Challenging the stereotypes: men, withdrawal, and reproductive health in Lebanon. Contraception. 2002;65(2):165-170.

5. Eini-Zinab H, Kazemipour S, Delavar B, Mehryar AH, Aghajanian A. Continuing use of withdrawal as a contraceptive method in Iran. Can Stud Popul. 2007;34(2):179-190. doi:10.25336/P6JK63

6. Abbasi-Shavazi MJ, McDonald P, Hosseini-Chavoshi M. The fertility transition in Iran: Revolution and Reproduction. Dordrecht: Springer; 2009.

7. Iran Ministry of Health and Medical Education. Iran Demographic and Health Survey. Tehran: Iran Ministry of Health and Medical Education; 2002. [Persian].

8. Rashidian A, Khosravi A, Arab M, et al. Indicator and Demographic Health Survey. 2010: Questionnaires, Guides and Protocols. Tehran, Iran: Notional Institute of Health Research and Deputy for Health, Ministry of Health and Medical Education; 2010.

9. Speroff L, Darny PD. A clinical guide for contraception. 3rd ed. Philadelphia: Lippincott Williams \& Wilkins; 2001.

10. Hubacher D, Suazo M, Terrell S, Pinel M. Examining the increasing prevalence of traditional contraceptive methods in Honduras. Int Fam Plan Perspect. 1996;22(4):163-168.

11. Aliakbari SA, Niyaki M, Ahmadi M, Alavi H. Cause of using a traditional method in Amol. Journal of Mazandaran University of Medical Sciences. 2001;15(48):92-98. [Persian].

12. Hosseini-Chavoshi M, Abbasi-Shavazi MJ. Unintended pregnancy among Iranian young women: incidence, correlates and outcomes. Asia Pac Popul J. 2015;30(1):85118. doi:10.18356/922d178c-en

13. de Irala J, Osorio A, Carlos S, Lopez-del Burgo C. Choice of birth control methods among European women and the role of partners and providers. Contraception. 2011;84(6):558564. doi:10.1016/j.contraception.2011.04.004

14. Dehlendorf C, Levy K, Ruskin R, Steinauer J. Health care providers' knowledge about contraceptive evidence: a barrier to quality family planning care? Contraception. 2010;81(4):292-298. doi:10.1016/j. contraception.2009.11.006

15. Mohseni Z. The Gap between Actual and Ideal Fertility in Tabriz [dissertation]. Yazd: Faculty of Social Science, Yazd University; 2018.

16. Azari S, Shahnazi M, Farshbafkhalili A, Abbasnezhad O. Reasons for choosing the traditional method (withdrawal) as contraception among women in Tabriz/Iran. International Journal of Women's Health and Reproduction Sciences. 2014;2(5):297-300. doi:10.15296/ijwhr.2014.48

17. Ergocmen BA, Koc I, Senlet P, Yigit EK, Roman E. A closer look at traditional contraceptive use in Turkey. Eur J Contracept Reprod Health Care. 2004;9(4):221-244.

18. Horner JR, Salazar LF, Romer D, et al. Withdrawal (coitus interruptus) as a sexual risk reduction strategy: perspectives from African-American adolescents. Arch Sex Behav. 2009;38(5):779-787. doi:10.1007/s10508-007-9304-y

19. Rahman H, Khalda E, Kar S, Kharka L, Bhutia GP. Knowledge of, attitudes toward, and barriers to the practice of emergency contraception among women in Sikkim, India. Int J Gynaecol Obstet. 2013;122(2):99-103. doi:10.1016/j.ijgo.2013.03.016

20. Shahamfar J, Kishore J, Shokhvash B. Effects of educational intervention on male participation in family planning in Iran. Health Popul Perspect Issues. 2007;30(4):292-299.

21. Sirkeci I, Cindoglu D. Space, agency, and withdrawal: birth control choices of women in Turkey. Health Care Women Int. 2012;33(7):614-630. doi:10.1080/07399332.2012.6553 84

22. Erfani A, Yuksel-Kaptanoglu I. The use of withdrawal among birth limiters in Iran and Turkey. Stud Fam Plann. 2012;43(1):21-32.

23. Whittaker PG, Merkh RD, Henry-Moss D, Hock-Long L. Withdrawal attitudes and experiences: a qualitative perspective among young urban adults. Perspect Sex Reprod Health. 2010;42(2):102-109. doi:10.1363/4210210

24. Jones RK, Lindberg LD, Higgins JA. Pull and pray or extra protection? Contraceptive strategies involving withdrawal among US adult women. Contraception. 2014;90(4):416421. doi:10.1016/j.contraception.2014.04.016

25. Ortayli N, Bulut A, Ozugurlu M, Cokar M. Why withdrawal? Why not withdrawal? Men's perspectives. Reprod Health Matters. 2005;13(25):164-173. doi:10.1016/ S0968-8080(05)25175-3

26. Razeghi Nasrabad HB, Saadati M, Bagheri A. Factors Affecting Unplanned Pregnancy in Semnan Province, Iran. Journal of Midwifery and Reproductive Health. 2018;6(2):1273-1281. doi:10.22038/jmrh.2018.10475

27. Rahnama P, Hidarnia A, Amin Shokravi F, Kazemnejad A, Oakley D, Montazeri A. Why Iranian married women use withdrawal instead of oral contraceptives? A qualitative study from Iran. BMC Public Health. 2010;10(1):289. doi:10.1186/1471-2458-10-289

(c) 2019 The Author (s); This is an open-access article distributed under the terms of the Creative Commons Attribution License (http://creativecommons.org/licenses/by/4.0), which permits unrestricted use, distribution, and reproduction in any medium, provided the original work is properly cited. 